\title{
Day Care or Confusion?
}

PhIllip J. Vaughan, Principal Social Worker in Psychiatry, Heatherwood Day Unit, King's Ride, Ascot, Berks.

Over thirty-five years have elapsed since Dr Joshua Bierer opened the first psychiatric day unit in London in 1946. Following a somewhat tentative start in the early 1950 s, day hospitals expanded rapidly during the latter 1950 s, ' 60 s and into the '70s, and are now regarded as an established part of the psychiatric services. However, it is probably a truism that many of the staff working in psychiatry know little more about the philosophy, practice and effectiveness of day care than their colleagues did a generation ago.

The use of day care emerged at a time of widespread change in the mental health field, being caught up in the movement away from institutional care to care in the community. Early enthusiasm for the movement appears to have been based on untested assumptions that it would offer a more economic and effective form of treatment, that it would reduce the demand for in-patient beds and that it would facilitate more productive contact with the patient's family. There is, however, very little evidence to support these suppositions, and the development of day hospitals and centres could be regarded as an expedient measure to meet the changing fashion in psychiatry.

\section{Day hospitals}

The concept of day hospital care seems to have been a useful compromise between institutional and community care, leading to a rapid development which quickly outstripped any attempts to question its validity. Without any central guiding philosophy the movement was left to develop in a rather ad hoc and unco-ordinated way, which has led to an extremely diversified range of day services. The style and philosophy of most current day hospitals is usually a reflection of the ideas and personality of the consultant in charge rather than a systematised part of a complete whole. Thus different day hospitals concentrate on different patient groups, or types of care and treatment. The emphasis may be on providing a specific range of treatments, social support, rehabilitation, long-term care, sheltered employment or any mixture of these options. Some operate as dropin centres while others have rigid referral systems; some require five-day week attendance, others only part-time attendance. Comparisons between one unit and another are virtually impossible and in its present forms the day care movement almost defies evaluation. The proven success of one particular unit may not necessarily be transferred to others as no two appear identical. The only unifying feature of day hospitals appears to be the fact that all patients attend on a daily basis and live in the community rather than in the hospital, although even in-patients are mixed with genuine day patients in some settings.

There is also evidence that some day hospitals have been used as dumping grounds for chronic patients discharged into the community.' Their attendance at the day unit produced no different type of activity or rehabilitation than they received as in-patients. In such instances day hospitals are little more than a different setting for the practice of inpatient psychiatry. By excluding such examples, however, it is very difficult to compare day patients with in-patients as the former are likely to be qualitatively different from the latter. The more seriously disturbed patients in the community probably bypass day care by way of police and emergency admissions, and large numbers of day patients never require in-patient care at all, being a group who would otherwise remain untreated in the community. True comparisons are difficult to make unless both types of treatment approaches are equally feasible and patients are randomly allocated to each.

Not surprisingly, there have been few studies of sufficient quality which show that day care has any particular merit over in-patient care. ${ }^{2}$ One such study which has been conducted showed that day treatment is superior on measures of role function and psychopathology, but does not state why day treatment proved superior. ${ }^{3}$

Another vital area consistently neglected by such studies is the effect such an approach has on the family. Almost without exception, evaluative studies show a lack of concern for the views of relatives, despite them often having to bear the burden once born by the hospital. There is an unwarranted assumption that the patient will fare better if he is kept at home for nights and weekends. While undoubtedly true for some, the reverse is true for others; added to which the family may be needlessly stressed. Unfortunately there are few day hospitals which include the patients' family in the treatment process in the way originally envisaged by Bierer. Thus families are frequently imposed upon and excluded from treatment.

Furthermore, little thought or preparation is offered to staff moving into day hospital work. As there is no specific body of knowledge to draw upon to distinguish day care from in-patient care, nursing staff transfer into day settings and simply bring institutional ideas with them. In view of their closer proximity to the community, it could be argued that day patients will have a greater need for rehabilitation and social skills. There is no evidence, however, to show that nurses in day care are any better equipped to provide this type of input than their institutional colleagues. Occupational therapists, who are likely to be better trained and experienced in providing such a service, usually have to assume a subordinate role within what is still commonly a medically-oriented setting.

What we need to know, and what research has yet to 
show us, is: What type of patient benefits best from part-time psychiatry? How do their needs differ from in-patients? What unique skills are needed by day care staff? If day care is effective, what is it that is providing the benefit? Is it continued contact with the community, the self-discipline of having to attend the unit, the therapeutic activities engaged in, or simply the 'fellowship' provided by fellow patients? These and many other questions remain unanswered, and until they are, day hospitals are unlikely to develop in a more sophisticated and unified way than at present.

\section{Day centres}

Although day hospitals have yet to define their uniqueness within the psychiatric service, at least they have a traditional organization and basic expertise behind them. Day centres on the other hand are relative newcomers to the day care scene, but are equally diverse and lack any sense of identity or direction. There is much confusion about their purpose and function. It is certainly not clear about what day centres have additionally contributed to day care for the mentally ill apart from increasing the number of places available.

According to the government white paper Better Services for the Mentally Ill, ${ }^{5}$ local authority social services departments should provide psychiatric day centres primarily for chronic sufferers needing rehabilitation and long-term support. It is recommended that the treatment of acute psychiatric conditions be the main function of day hospitals. However, this does nothing but create an artificial dichotomy within the day care services, causing much confusion about role divisions. In reality there is usually very little difference between the two services in terms of activities provided, type of patient served or outcome. ${ }^{6}$ Day centres, however, provide only 25 per cent of day care places not having increased in any number until 1971, when the new social services departments took over responsibility for developing community mental health services. Unfortunately, little importance or status appears to have' been accorded to this new service with a result that the spread of trained staff with technical and therapeutic skills is parsimonious. Even scarcer is any attempt to evaluate the activities or efficacy of day centres, with most accounts being of a descriptive nature. Little is known about the effectiveness of the day centres as opposed to day hospitals and less about the value of having two separate services.

In any event local authorities have fallen far short of the number of day care places it is recommended they should provide and those that have emerged do not form any overall pattern of development. The outcome has been an impromptu expansion of services leading to as diversified a range of day centres as there is of day hospitals.

\section{Conclusions}

The opportunity to use day care as a means of developing the notion of community psychiatry, has to a large extent been missed. Bierer's original idea of creating a separate and independent psychiatric day care facility, offering a comprehensive range of treatments for the patient, his family and wider social circle, ${ }^{7}$ has not been realized. The concept of part-time care and treatment has been readily accepted, but only as an apparently cheaper way of providing a traditional service.

Development has been patchy, with some areas of the country well served by a variety of establishments, while others have none. This is particularly evident in the local authority provision of day centres. Lack of any overall planning or dovetailing of the separate services provided by health authorities and social services departments has robbed the movement of much of its promise.

Although common sense dictates that there is a place for day treatment in psychiatry and many claims are made for its success, little thought has been given about the way in which day care should differ from care and treatment in other settings. If it is a more successful way of treating patients than other means, it is important to know why it is more successful. Moreover, there are indications that day care works better if certain patients, such as disturbed psychotics, are excluded. Separate units may be a better option for this group. However, it is probably accurate to say that the day care approach is an appropriate form of treatment for some patients at certain stages of illness. There is a need to be clearer about which patients and what stages of illness.

If the flexibility and uniqueness of day care is to be utilized to its fullest extent, the advantages of day care per se must be identified by well planned research and evaluation. The alternative is a continuation of a service which has never been given a chance to develop its potential.

\section{REFERENCES}

' Gath, D. H., Hassall, G., \& Cross, K. W. (1973) Whither psychiatric day care? A study of day patients in Birmingham. British Medical Journal, $i$, 94-98.

${ }^{2}$ Meltzoff, J. \& Blumenthal, R. L. (1966) The Day Treatment Centre. Springfield: Charles $C$. Thomas.

${ }^{3}$ Hertz, M. I., Endicott, J., Sptrzer, R. L. \& Mesnikoff, A. (1971) Day versus in-patient hospitalisation: a controlled study. American Journal of Psychiatry, 127, 1371-82.

${ }^{4}$ Bender, M. (1983) Day centres: for what and for whom? Community Care, 13 January, 20-21.

'DHSS (1975) Better Services for the Mentally III. London: HMSO.

- CARTER, J. (1981) Day Services for Adults. London: George Allen \& Unwin.

' BIERER, J. (1951) The Day Hospital. London: H. K. Lewis. 